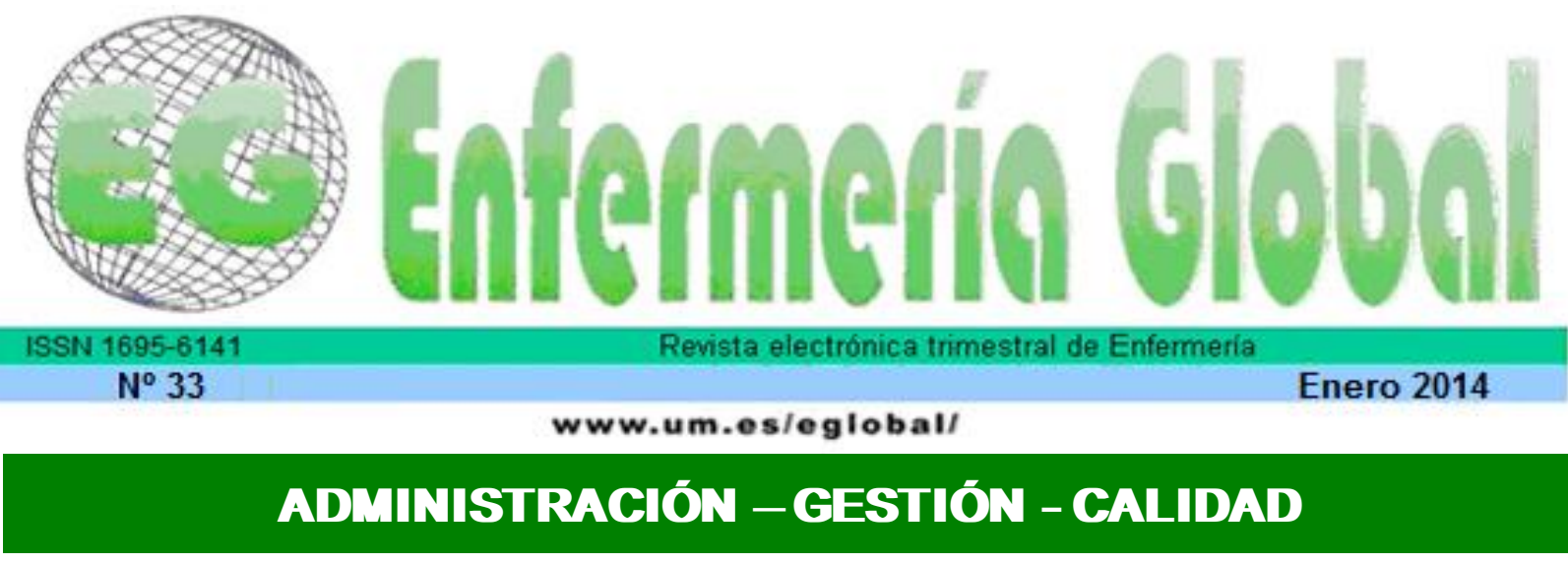

\title{
Trabajadores del área de salud de un hospital oncológico colonizados por microorganismos multidroga resistentes
}

Trabalhadores da área de saúde de um hospital oncológico colonizados por micro-organismos multi-droga-resistentes

Oncology hospital health workers colonized by multi-drug resistant microorganisms

\section{*Trindade, Júnnia Pires de Amorim **Goulart Rodrigues, Érika **de Sousa, Thais Kato ${ }^{* * *}$ Prado Palos, Marinésia Aparecida ${ }^{* * *}$ Vieira dos Santos, Silvana de Lima}

\begin{abstract}
*Estudiante de la Facultad de Enfermería. Voluntaria del Programa Institucional de Iniciación Científica PIVIC/CNPq/UFG. Miembro del Núcleo de Estudios e Investigación de Enfermería en Prevención y Control de Infecciones Relacionadas com la Asistencia a la Salud - NEPIH. E-mail: junniatrindade@gmail.com **Graduada en Enfermería ***Enfermera. Doctora. Profesor Adjunto de la FEN/UFG, Pesquisadora del NEPIH. Brasil.
\end{abstract}

\begin{abstract}
Palabras clave: Farmacorresistencia bacteriana; farmacorresistencia bacteriana múltiple; exposición profesional; desinfección de las manos.
\end{abstract}

Palavras chave: Farmacorresistência bacteriana; farmacorresistência bacteriana múltipla; exposição ocupacional; lavagem de mãos

Keywords: Drug Resistance; bacterial; drug resistance; multiple; occupational exposure; bacterial hand disinfection.

\section{RESUMEN}

Estudio transversal con trabajadores de salud en un Hospital de referencia en oncología de 02/2009 a 12/2010. Se objetivó caracterizar el perfil de los profesionales colonizados por microorganismos multirresistentes y verificar su adhesión a Higiene de las Manos y utilización de Equipamientos de Protección Individual (EPI). Para identificarlos, se utilizó entrevista, recolección de saliva y análisis microbiológicos. Datos tratados con SPSS ${ }^{\circledR}$ 19.0. Se observaron aspectos éticos (protocolo 040/08). Se encontraron 148 profesionales colonizados, $29,7 \%$ por microorganismos multirresistentes. El $75 \%$ trabajaba 40 horas semanales o más. Sin relación entre categoría profesional y estar colonizado, ni entre estar colonizado y vínculos laborales. Todos refirieron higienizar sus manos, la mayoría con frecuencia $(97,8 \%)$. Respecto al EPI, 91\% informó su utilización. Teniendo en cuenta la población atendida, se verifica la necesidad de reforzar medidas preventivas y de control de infecciones en la institución, entre ellas, implantar vigilancia microbiológica activa de los profesionales. 


\section{RESUMO}

Estudo transversal com trabalhadores da saúde em um Hospital referência em oncologia de 02/2009 a 12/2010. Objetivou-se caracterizar o perfil dos profissionais colonizados por micro-organismos multirresistentes e verificar a adesão desses a Higienização das Mãos e ao uso dos Equipamentos de Proteção Individual (EPI). Para a identificação destes utilizou-se de entrevista, coleta de saliva e análises microbiológicas. Tratamento dos dados no Software SPSS ${ }^{\circledR} / 19.0$. Observou-se os aspectos éticos (protocolo-040/08). Colonizados 148 profissionais sendo por micro-organismos multirresistentes $29,7 \%$. Trabalhavam 40 horas semanais ou mais $75 \%$. Não houve relação entre a categoria profissional e estar colonizado, nem estar colonizado e vínculos de trabalho. Todos referiram higienizar as mãos e realizá-la com frequência (97,8\%). Quanto ao EPI verificou-se que $91 \%$ relataram a sua utilização. Tendo em vista a população assistida verifica-se que é necessário reforçar as medidas de prevenção e controle de infecções da instituição estando dentre essas a vigilância microbiológica ativa dos profissionais.

\section{ABSTRACT}

Cross-sectional study conducted with health workers of an Oncology Hospital between 02/2009 and 12/2010. The objective was to characterize the profile of workers colonized by multi-drug resistant microorganisms and identity their adherence to Hand Washing and Personal Protective Equipment (PPE). The subjects were interviewed, a sample of saliva was collected and microbiological analyses were performed. Data were treated using SPSS $\AA / 19.0$. All ethical aspects were considered (protocol040/08). A total of 148 workers were colonized, $29.7 \%$ by multi-drug resistant microorganisms. Most $(75 \%)$ worked 40 weekly hours or more. It wasn't found any relationship between the professional category and being colonized, or between being colonized and types of work contracts. All subjects reported washing hands; $97.8 \%$ frequently. Regarding PPE, 91\% reported adherence. Infection control and prevention measures at the studied institution must be improved, which includes an active microbiological surveillance of workers.

\section{INTRODUCCIÓN}

Los trabajadores de salud están expuestos a varios riesgos en razón de la actividad que desempeñan en las instituciones de salud, consideradas lugares insalubres. Tales riesgos pueden clasificarse como físicos, químicos, psicológicos, mecánicos y biológicos ${ }^{\top}$. Los riesgos profesionales relacionados con agentes biológicos están ampliamente distribuidos en la estructura de una unidad de salud, resultando ello más evidente cuando se involucra el contacto directo con sangre, secreciones y otros fluidos corporales ${ }^{2}$.

El riesgo biológico es la probabilidad de exposición laboral a agentes biológicos como: microorganismos genéticamente modificados o no; cultivos celulares; parásitos, toxinas y priones ${ }^{3}$.

En su labor, los profesionales del área de salud no sólo se deparan con los citados agentes, sino también con bacterias resistentes a los antimicrobianos en razón del uso inadecuado de estos, lo cual hace que tales bacterias se vuelvan multirresistentes, representando así un importante problema para la salud del trabajador ${ }^{4}$.

La aparición de la resistencia a antibióticos y otras drogas es uno de los grandes problemas en las instituciones de salud, desde el punto de vista clínico y la salud pública, dado que el incremento de resistencia de las bacterias patogénicas puede resultar más rápido que la capacidad de la industria farmacéutica para desarrollar nuevas drogas ${ }^{5,6}$. 
Ante esta situación, resulta imprescindible la realización de vigilancia de los profesionales del área de salud que atienden pacientes oncológicos, buscando colonizaciones de estos microorganismos, apuntando al establecimiento de criterios para disminuir los riesgos de colonización del trabajador y del paciente, el tiempo de internación y los costos de los tratamientos. En ese sentido, este estudio tuvo el propósito de caracterizar el perfil de los profesionales colonizados por microorganismos multirresistentes y verificar su adhesión a la Desinfección de Manos y al uso de los Equipamientos de Protección Individual (EPI).

Los microorganismos multirresistentes a drogas (MMRD) son aquellos resistentes a una o más clases de agentes antimicrobianos y, generalmente, resistentes a casi el total (exceptuando a uno o dos) antibióticos comercialmente disponibles ${ }^{7}$.

En este contexto, los MMRD merecen atención por parte de los profesionales del área de salud, ya que muchos de estos trabajadores desconocen su condición de portadores de microorganismos. Dicho desconocimiento facilita que el trabajador colonizado los disperse, tanto en su ambiente de trabajo como en otros lugares, principalmente cuando entra en contacto con los pacientes durante la atención, así como también facilita adquirirlos durante el proceso de trabajo ${ }^{8}$.

En relación a la colonización por MMRD durante la atención de la salud, merecen destacarse las instituciones con atención especializada a pacientes sometidos a terapias oncológicas. Tal hecho se justifica en razón de que estos pacientes presentan déficit inmunológico, situación que favorece su colonización y el consecuente desarrollo de infecciones graves ${ }^{8}$. El diagnóstico de infección puede resultar difícil en este tipo de pacientes, no sólo por la diversidad de agentes microbianos utilizados en su terapia, sino también por las peculiaridades de la presentación clínica ${ }^{9}$.

Ante estas evidencias, deben implementarse medidas por parte de las instituciones de salud para el control de la diseminación de los MMRD entre profesionales colonizados y pacientes.

Entre las medidas de seguridad del paciente y el trabajador recomendadas en el contexto de la salud, se enfatiza la importancia de la desinfección de manos, como patrón-oro, para todos los profesionales, visitantes y acompañantes. Sumadas a tal medida, se incluye el refuerzo de la aplicación de precauciones basadas en el contagio, además de las precauciones estándar para las personas que, en algún momento, entren en contacto con pacientes que se sepa que están colonizados ${ }^{10}$.

\section{METODOLOGÍA}

Estudio descriptivo, de tipo transversal, realizado con trabajadores del área de salud de un Hospital de referencia en tratamiento oncológico, integrado al Sistema Único de Salud (SUS) en Goiânia - Goiás, en el período de febrero de 2009 a diciembre de 2010.

La población se constituyó de 295 profesionales que formaban parte de los equipos de salud (médicos, enfermeros, técnicos y auxiliares de enfermería, fisioterapeutas, fonoaudiólogos, farmacéuticos, nutricionistas, odontólogos e instrumentistas quirúrgicos), y trabajadores de los servicios de Procesamiento de Ropas, Higiene y Limpieza, además de secretarios, técnicos en radioterapia, auxiliares de yeso, 
cocineros y personal gastronómico. Se incluyeron en la muestra a los profesionales que brindaban atención directa a los pacientes en uno de los sectores descritos, ejercía función/cargo administrativo en el servicio de terapia intensiva (STI) y que estuviese presente en el hospital al momento de la recolecta. Los trabajadores que ejercían función/cargo administrativo, excepto en el STI, y aquellos que estaban en tratamiento con antimicrobianos o habían hecho uso de ellos en los últimos siete días previos a la recolección resultaron excluidos. Se consideró para los profesionales colonizados con MMRD, estar colonizado con microorganismos resistentes a una 0 más clases de antimicrobianos, o microorganismos resistentes a la droga de elección para su tratamiento de acuerdo a las recomendaciones del Center for Disease Control and Prevention ${ }^{7}$.

La recolección de datos fue realizada a través de dos estrategias: aplicación de un cuestionario evaluado por tres especialistas en el área y test piloto, seguida de colecta de saliva de los sujetos. El cuestionario se compuso de preguntas abiertas y cerradas que contemplaron datos personales y profesionales pertinentes al tema y a los objetivos propuestos. Fueron abordadas cuestiones tales como escolaridad, edad, tiempo de actuación en la institución, función actual, turno de trabajo, horas semanales de trabajo, trabajo en otras instituciones de salud, uso de EPI en la atención y adhesión a la higienización de las manos.

Para la identificación de los profesionales colonizados por microorganismos multirresistentes, la saliva colectada fue enviada al laboratorio de bacteriología del Instituto de Patología Tropical y Salud Pública (IPTSP). Los análisis laboratoriales microbiológicos de aislamiento, identificación y antibiograma siguieron las técnicas recomendadas por el Clinical and Laboratory Standards Institute (CLSI) ${ }^{11}$. Los mismos fueron llevados a cabo por el grupo de investigación compuesto por alumnos de doctorado y maestría del proyecto llamado Microorganismos aislados en la saliva de profesionales de salud y áreas de apoyo de un Hospital Oncológico de la Región Centro-Oeste de Brasil, el cual dio origen a este estudio.

El proyecto fue aprobado por el Comité de Ética en Investigación de la Asociación de Combate contra el Cáncer en Goiás (CEP/ACCG), bajo protocolo CEPACCG/040/08. Posteriormente, se inició la recolección de datos, con la presentación de los objetivos y aceptación de los sujetos mediante la firma del Término de Consentimiento Libre y Esclarecido (TCLE).

Los datos fueron procesados y analizados con el Software Statistical Package for the Social Sciences - SPSS ${ }^{\circledR}$ (versión 19.0). Se efectuaron procedimientos de estadística descriptiva e inferencial (test de Chi-cuadrado y Exacto de Fisher), adoptándose $\mathrm{p}<0,05$.

\section{RESULTADOS}

Participaron 295 profesionales, de los que 148 se encontraban colonizados por bacterias. Los microorganismos aislados fueron analizados respecto de su perfil de resistencia, y se verificó que, de los profesionales colonizados, 44 (29,7\%) lo estaban por microorganismos multirresistentes, cepas de Staphylococcus coagulasa negativos (ECN) resistentes a la meticilina.

Al respecto del sexo de los participantes, predominó el femenino con $37(84,1)$, con edades entre 22 y 61 años, media de 39,2 años. Se observó que el nivel de escolaridad de 28 (63,6\%) de los trabajadores era enseñanza media, el de $12(27,3 \%)$ 
enseñanza superior y el de $4(9,1 \%)$ enseñanza primaria. En relación al tiempo de actuación, la misma varió entre 0 y 324 meses (27 años), con media de 90 meses (7,5 años). En referencia a la carga horaria, 11 (25\%) informó trabajar menos de 40 horas semanales y $33(75 \%)$ reportaron carga horaria mayor o igual a 40 horas semanales. Entre los turnos de trabajo, prevalecieron el diurno, $24(54,5 \%)$ y el matutino, 10 $(22,8 \%)$.

Acerca del área de actuación de los profesionales colonizados por MMRD, los más afectados fueron los técnicos de enfermería, 23 (52,2\%). Al verificarse la relación entre la categoría profesional y el hecho de estar colonizado por microorganismos multirresistentes, la misma no fue observada (Tabla 1).

Tabla 1. Distribución de los profesionales colonizados con microorganismos multirresistentes, según su categoría profesional $(n=44)$. Goiânia - GO.

\begin{tabular}{|c|c|c|c|c|c|c|}
\hline \multirow[b]{2}{*}{ Categoría Profesional } & \multicolumn{2}{|c|}{$\begin{array}{l}\text { Colonizados } \\
\text { multirresistentes }\end{array}$} & \multirow{2}{*}{$\begin{array}{l}\text { con } \\
\text { No } \\
\end{array}$} & \multicolumn{3}{|c|}{ microorganismos } \\
\hline & Sí & & & & $\mathrm{X}^{2}$ & $P$ \\
\hline & $\mathrm{N}$ & $(\%)$ & $\mathrm{n}$ & $(\%)$ & & \\
\hline Médico & 1 & 2,3 & 9 & 3,6 & 0,197 & 0,545 \\
\hline Enfermero & 4 & 9,1 & 8 & 3,2 & 3,344 & 0,086 \\
\hline Técnico de Enfermería & 23 & 52,3 & 115 & 45,8 & 1,661 & 0,197 \\
\hline Servicio de higienización y limpieza & 6 & 13,6 & 64 & 25,5 & 2,910 & 0,088 \\
\hline Personal Gastronómico & 7 & 15,9 & 29 & 11,6 & 0,121 & 0,728 \\
\hline Técnico en Radiología & 1 & 2,3 & 5 & 2,0 & 0,002 & 0,719 \\
\hline Auxiliar Administrativo & 1 & 2,3 & 1 & 0,4 & 0,810 & 0,385 \\
\hline Instrumentista Quirúrgico & 1 & 2,3 & 2 & 0,8 & 0,849 & 0,694 \\
\hline
\end{tabular}

Categoría profesional y colonizados con microorganismos multirresistentes $\left(\mathrm{X}^{2}\right.$ : 12,445; p: 0,200).

Al considerarse el vínculo laboral de los profesionales colonizados, 26 (59\%) tenían vínculo sólo con la institución estudiada, y 18 (41\%) poseían vinculaciones con otras instituciones. Verificando la relación entre la categoría profesional de los trabajadores colonizados con microorganismos multirresistentes y el vínculo laboral, la misma no fue observada (Tabla 2). 
Tabla 2. Distribución de la categoría profesional de trabajadores colonizados con microorganismos multirresistentes $(n=44)$, de acuerdo con vínculo laboral en una institución o más. Goiânia - GO.

\begin{tabular}{lllllll}
\hline & \multicolumn{6}{l}{$\begin{array}{l}\text { Vínculo solamente con la institución de salud del } \\
\text { estudio }\end{array}$} \\
\cline { 2 - 8 } Categoría Profesional & Sí & & No & & $X^{2}$ & $\mathrm{P}$ \\
\hline & $\mathrm{n}$ & $\%$ & $\mathrm{n}$ & $\%$ & & \\
\cline { 2 - 8 } Enfermero & 1 & 2,3 & 0 & 0,0 & 0,274 & 0,487 \\
Técnico en Enfermería & 11 & 25,0 & 12 & 4,8 & 0,175 & 0,676 \\
Auxiliar de enfermería & 6 & 13,6 & 0 & 0,0 & 0,430 & 0,512 \\
Otros & 8 & 18,2 & 0 & 0,0 & 0,575 & 0,448
\end{tabular}

Vínculo con otras instituciones de salud

\begin{tabular}{lllllll}
\cline { 2 - 6 } Categoría Profesional & Sí & \multicolumn{3}{c}{ No } & $\mathrm{X}^{2}$ & $\mathrm{P}$ \\
\hline \multirow{n}{*}{$\mathrm{n}$} & $\%$ & $\mathrm{~N}$ & $\%$ & & \\
Médico & 1 & 2,3 & 0 & 0,0 & 0,510 & 0,422 \\
Enfermero & 3 & 6,8 & 3 & 1,2 & 1,823 & 0,185 \\
Técnico en Enfermería & 12 & 27,3 & 2 & 0,8 & 0,601 & 0,438 \\
Otros & 2 & 4,5 & 0 & 0,0 & 0,136 & 0,529
\end{tabular}

Vínculo con la institución del estudio ( $X^{2}$ : 14,773; p: 0,01); Vínculo con otras instituciones ( $\left.X^{2}: 4,107 ; p: 0,300\right)$

Acerca de la desinfección de las manos, al preguntársele sobre la ejecución durante la atención, todos los participantes informaron efectuarla, y $43(97,8)$ refirieron higienizarlas con frecuencia.

Sobre las situaciones de atención de la salud en las cuales los profesionales colonizados higienizan sus manos, $42(95,5 \%)$ manifestaron higienizarlas luego de la remoción de los guantes, $39(88,7 \%)$ luego del procedimiento, $38(86,4 \%)$ antes del procedimiento, $30(68,2 \%)$ al realizar procedimientos en diferentes pacientes, 25 $(56,8 \%)$ entre procedimientos con el mismo paciente y $2(4,6 \%)$ no tenían el hábito de desinfectar sus manos entre pacientes diferentes (Tabla 3 ).

Al consultárselos sobre la atención a individuos cuya colonización se conoce, 28 (64\%) profesionales entrevistados refirieron que higienizaban sus manos con la misma frecuencia que cuando brindaban cuidados a individuos no colonizados, y 16 (36\%) expresaron que no higienizaban sus manos con la misma frecuencia. 
Tabla 3. Distribución de la frecuencia y porcentaje de trabajadores colonizados con microorganismos multirresistentes, según situaciones en la atención de la salud en las cuales los mismos higienizan sus manos ( $n=44)$. Goiânia - GO.

\begin{tabular}{|c|c|c|c|}
\hline \multirow{3}{*}{$\begin{array}{l}\text { Situaciones } \\
\text { Higienización de las manos } \\
\text { antes del procedimiento }\end{array}$} & \multicolumn{3}{|c|}{ Higienización de las Manos } \\
\hline & $f$ & & $(\%)$ \\
\hline & $\begin{array}{l}\text { No } \\
\text { Sí } \\
\text { No se aplica }\end{array}$ & $\begin{array}{l}1 \\
38 \\
5\end{array}$ & $\begin{array}{l}2,3 \\
86,4 \\
11,3\end{array}$ \\
\hline $\begin{array}{l}\text { Higienización de las manos } \\
\text { después del procedimiento }\end{array}$ & $\begin{array}{l}\text { No } \\
\text { Sí } \\
\text { No se aplica }\end{array}$ & $\begin{array}{l}0 \\
39 \\
5\end{array}$ & $\begin{array}{l}0,0 \\
88,7 \\
11,3\end{array}$ \\
\hline $\begin{array}{l}\text { Higienización de las manos } \\
\text { entre procedimientos con el } \\
\text { mismo paciente }\end{array}$ & $\begin{array}{l}\text { No } \\
\text { Sí } \\
\text { No se aplica }\end{array}$ & $\begin{array}{l}9 \\
25 \\
10\end{array}$ & $\begin{array}{l}20,5 \\
56,8 \\
22,7\end{array}$ \\
\hline $\begin{array}{l}\text { Higienización de las manos } \\
\text { entre diferentes pacientes }\end{array}$ & $\begin{array}{l}\text { No } \\
\text { Sí } \\
\text { No se aplica }\end{array}$ & $\begin{array}{l}2 \\
30 \\
12\end{array}$ & $\begin{array}{l}4,6 \\
68,2 \\
27,2\end{array}$ \\
\hline $\begin{array}{l}\text { Higienización de las manos } \\
\text { luego de quitarse los guantes }\end{array}$ & $\begin{array}{l}\text { No } \\
\text { Sí } \\
\text { No se aplica }\end{array}$ & $\begin{array}{l}0 \\
42 \\
2\end{array}$ & $\begin{array}{l}0,0 \\
95,5 \\
4,5\end{array}$ \\
\hline $\begin{array}{lr}\text { Higienización de las manos } \\
\text { con igual frecuencia para } \\
\text { pacientes colonizados } \\
\text { multirresistentes y y no } \\
\text { colonizados }\end{array}$ & $\begin{array}{l}\text { No } \\
\text { Sí } \\
\text { No se aplica }\end{array}$ & $\begin{array}{l}16 \\
28 \\
0\end{array}$ & $\begin{array}{l}36,3 \\
63,7 \\
0,0\end{array}$ \\
\hline
\end{tabular}

En relación al uso de EPI por parte de los trabajadores colonizados por MMRD, se verificó que 40 (91\%) utilizaba EPI, y $2(4,5 \%)$ informaron no utilizarlos.

\section{DISCUSIÓN}

De acuerdo con la cadena epidemiológica de infección, gotículas de saliva cargadas de microorganismos virulentos pueden constituir una fuente de contaminación cruzada y, consecuentemente, provocar la colonización de pacientes y trabajadores. Dicho mecanismo condiciona la diseminación de tales agentes, tanto en el ambiente hospitalario como en la propia comunidad ${ }^{12}$. De este modo, identificar profesionales del área de salud colonizados por microorganismos se configura como un riesgo para la seguridad de los pacientes ${ }^{13}$.

Ese riesgo aumenta al verificarse la presencia de microorganismos multirresistentes a los antimicrobianos de última generación, tales como los del género Staphylococcus, importantes patógenos asociados a infecciones hospitalarias ${ }^{14}$.

Estas bacterias provienen de la microbiota transitoria de la piel de hasta un tercio de la población en general, y se las ha asociado comúnmente con infecciones en pacientes adultos con factores de riesgo tales como: ingresos prolongados, uso de antimicrobianos, procedimientos invasivos, cirugías y pacientes sometidos a hemodiálisis o diálisis peritoneal ${ }^{15}$.

En el presente estudio fueron identificadas cepas de Staphylococcus coagulasa negativos resistentes a la meticilina (ECN). Dichos microorganismos son de extrema 
importancia, pues colonizan naturalmente la piel y las mucosas, causando infecciones en el sitio primario de infección o pueden incluso diseminarse, causando bacteriemia y septicemia $^{16}$. Los ECN son frecuentemente reconocidos como una de las principales causas de infecciones de la corriente sanguínea intrahospitalarias en pacientes críticos, pudiendo llevarlos a la morbilidad e incluso al deceso ${ }^{17}$.

Los estudios refieren que la prevalencia de ECN resistentes a oxacilina es elevada en la mayoría de los hospitales de Brasil y del mundo, y la identificación de las especies de dicho grupo es de extrema importancia, ya que se las relaciona frecuentemente con septicemias neonatales, infecciones en pacientes inmuno-comprometidos y bajo nutrición parenteral total, además de pacientes postquirúrgicos y usuarios de dispositivos intravasculares ${ }^{16,18}$.

En un estudio que objetivó evaluar la prevalencia de $S$. coagulasa negativo resistente a oxacilina en la saliva de profesionales de la salud, se obtuvo prevalencia de 32 $(32 \%)^{16}$, superando lo hallado en el presente estudio, que fue de $29,7 \%$. En relación al área de actuación de los colonizados con MMRD, sobresalieron los técnicos de enfermería. En las instituciones de salud, la enfermería incluye a la mayor porción de profesionales del área de salud, lo cual justifica una mayor representatividad de la categoría $^{19,20}$.

La asociación de la categoría profesional con la colonización por MMRD no presentó diferencia estadísticamente significativa $(p>0,05)$, coincidiendo con estudios que verificaron la no asociación entre la colonización por MRSA y las diferentes categorías de profesionales de salud investigados ${ }^{21}$. Ya otros estudios verificaron la existencia de relación entre categoría profesional y colonización por microorganismos multirresistentes ${ }^{19,20}$. Entre las variables estudiadas, la faja etaria y la cantidad 0 disponibilidad de EPI mostraron asociación con la colonización ${ }^{21}$.

Existe evidencia de que la colonización sucede en mayor grado entre los técnicos de enfermería; dichas evidencias pueden justificarse por el hecho de que tales profesionales pasan más tiempo en contacto con pacientes potencialmente infectados o colonizados, así como por la escasa adhesión de los mismos a la higienización de las manos y al uso de EPI ${ }^{14,32}$.

El vínculo laboral del trabajador con una o más instituciones de salud potencia el riesgo de exposición laboral a los MMRD. Por otra parte, los resultados recabados acerca de dicho aspecto no evidenciaron asociación con el hecho de estar colonizado. Aunque no exista asociación, debe recordarse que las instituciones de salud son ambientes insalubres, y los trabajadores están expuestos constantemente a estos agentes. De todos modos, fue poco significativa la presencia o no de colonización entre aquellos trabajadores que informaron trabajar en una o más instituciones ${ }^{20}$.

Además, es sobremanera conocido que la adhesión a la técnica adecuada de higienización de manos por parte de los profesionales es fundamental para la reducción de la dispersión de MMRD. Esa medida está fundamentada en el hecho de que estos pueden estar directamente involucrados en la dispersión de los microorganismos, principalmente en las actividades enfocadas en la atención del paciente ${ }^{23}$.

Se resalta también la capacidad de los patógenos resistentes para mantenerse en las manos, objetos inanimados y superficies, y de transmitirse de un paciente a otro 
cuando los profesionales de salud no adhieren a la higienización de las manos, perpetuándose así la cadena de transmisión ${ }^{23}$.

Los resultados del presente estudio demostraron que todos los profesionales colonizados por MMRD informaron higienizar sus manos, siendo que las situaciones incluidas en la atención en las que tal procedimiento fue llevado a cabo presentaron mayores frecuencias, después de la remoción de guantes $(95,5 \%)$, realización de procedimiento $(88,7 \%)$ y antes del procedimiento $(86,5 \%)$. Aunque se trata de un número poco significativo, se destaca el hecho de que 2 profesionales $(4,6 \%)$ afirmaron no higienizarse las manos entre procedimientos en pacientes diferentes. Dicha actitud está en franco desacuerdo con las directivas de seguridad del paciente y del trabajador, teniendo en cuenta de que tal medida es esencial para evitar la contaminación cruzada y la consecuente dispersión de estos microorganismos de un paciente a otro.

A pesar de los resultados obtenidos, los estudios evidencian la baja adhesión a la técnica de desinfección de las manos, siendo que de 43 profesionales observados en el servicio de terapia intensiva neonatal de un hospital, $56 \%$ higienizaba sus manos (HM) al ingresar en la unidad, no adhiriendo ninguno de ellos a la utilización de la técnica recomendada ${ }^{25,26,27,28}$.

Un estudio que buscó evaluar la colonización por ECN resistente a la oxacilina en 100 profesionales antes y después de la HM evidenció una frecuencia de cuatro profesionales colonizados antes de dicha práctica, reduciéndose a un profesional colonizado luego de la adopción de la medida ${ }^{29}$.

Es importante destacar que la finalidad de la $\mathrm{HM}$ es la remoción de la microbiota transitoria que coloniza la superficie de la piel, la cual incluye microorganismos considerados de baja virulencia, como los $\mathrm{ECN}^{24,25}$. Aún con ese perfil, vale recordar que para individuos inmuno-comprometidos, el desarrollo de infecciones por ECN puede resultar significativo ${ }^{30}$. Se resalta que la HM debe tener lugar antes y después del contacto con el paciente, antes de colocarse los guantes y después de retirarlos, entre un paciente y otro, entre un procedimiento y otro, o en ocasiones en las que pueda existir transferencia de patógenos al paciente $\mathrm{y} / \mathrm{o}$ al ambiente, entre procedimientos con el mismo paciente y luego del contacto con sangre, líquido corporal, secreciones, excreciones y artículos o equipamientos contaminados ${ }^{31}$.

Otra medida de protección utilizada por los profesionales del área de salud es el uso de EPI. Su uso fue informado por $91 \%$ de los profesionales colonizados por microorganismos multirresistentes, coincidiendo con un estudio que identificó que $97,2 \%$ de los profesionales refirió su utilización ${ }^{32}$.

Es necesario destacar que el uso de EPI es indispensable para romperr la cadena epidemiológica de los MMRD portados por trabajadores y pacientes de los servicios de salud; en particular, aquellos que brindan atención a personas inmunocomprometidas.

Estos resultados comprometen la calidad de atención, refuerzan la ocurrencia de fallas relacionadas con las actitudes de los profesionales respecto de la higienización de manos y utilización de EPI. Se resalta también que tales fallas se alejan de las directivas y principios de seguridad del paciente y del trabajador ${ }^{24,33}$. 


\section{CONCLUSIÓN}

El análisis de los datos del presente estudio permitió concluir que:

Los trabajadores de la institución investigada estaban colonizados por ECN resistentes a oxacilina, entre ellos predominó el sexo femenino, con edades variando de 22 a 61 años.

Respecto a la categoría profesional, hubo mayor representatividad por parte de los técnicos de enfermería y de los trabajadores del sector de higiene y limpieza. Existió prevalencia de profesionales con carga horaria semanal de 40 horas. La mayoría de los profesionales no poseían vínculo laboral con otras instituciones, sin embargo, no existió asociación entre categoría profesional, colonización por microorganismos multirresistentes y vínculo con otras instituciones.

La mayoría de los participantes refirió higienizar sus manos, priorizando la realización de tal medida después de quitarse los guantes, luego del procedimiento, antes del procedimiento, entre pacientes diferentes y/o procedimientos en el mismo paciente.

Más del $50 \%$ informó que realizaba la higiene de manos al brindar cuidados a individuos no colonizados, con la misma frecuencia que al atender a pacientes reconocidamente colonizados. El uso de EPI durante la atención a los pacientes fue mencionado por la mayoría de los profesionales.

El análisis de la colonización por microorganismos multirresistentes, trazando el perfil de los profesionales colonizados, debe constituir una rutina en las instituciones de salud, pues posibilita la planificación y evaluación de normas de control de infecciones por dichos agentes en los ámbitos de atención de la salud.

La prevención y el control de microorganismos multirresistentes se constituyen en un enorme desafío para las instituciones de salud de todo el mundo. Deben implementarse medidas de prevención y control de infecciones; en particular, la adopción de vigilancia activa de los profesionales (de cepas hospitalarias y de su perfil de sensibilidad), así como acciones educativas acerca de los riesgos y prevención de la transmisión y diseminación de microorganismos multirresistentes.

Deben observarse medidas simples de control de tales factores, como la ejecución de la higiene de manos, según la técnica, ante las situaciones recomendadas; además de la utilización de EPI.

Resulta indispensable destacar que la seguridad del paciente oncológico incluye indicadores que buscan la calidad de una atención brindada por trabajadores conscientes, capaces de percibir los riesgos inherentes a la colonización y eventual infección del paciente y del propio trabajador.

Siendo así, los resultados de este estudio señalan la necesidad de instituir un programa de capacitación continua en el servicio que agregue valores a todos los niveles profesionales, y que sobre todo estimule a los trabajadores en la búsqueda de conocimientos y valorización de la seguridad en el ámbito laboral. 


\section{REFERENCIAS}

1. Balsamo AC, FELLI, VE. Study of work accidents related to human body fluids exposure among health workers at a university hospital. Rev Latino-am Enfermagem. 2006; 14(3): 346-53.

2. Damasceno AP, Pereira MS, Souza ACS, Tipple AFV, Prado MA. Occupational accidents with biohazards: the perception of the injured worker. Rev Bras Enferm. 2006; 59(1): 72-7.

3. BRASIL. Portaria MTE no 485 de 11 de novembro de 2005. Norma regulamentadora segurança e saúde no trabalho em serviços de saúde - NR 32 . Diário Oficial da União. Brasília, DF, 16 nov. 2005. Seção 1. Acesso em: 7 jul 2012. Disponível em: www.mte.gov.br.

4. Silveira GP, Faruk N, Gesser JC, Sá MM. Estratégias utilizadas no combate à resistência bacteriana. Quim. Nova. 2006; 29(4): 844-55.

5. Mota RA, Silva KPC, Freitas MFL, Porto WJN, Silva LBG. Utilização indiscriminada de antimicrobianos e sua contribuição a multirresitência bacteriana. Braz $\mathrm{J}$ vet Res anim Sci. 2005; 42(6): 465-70.

6. Souza, C. S. Uma guerra quase perdida. Revista Ciência Hoje. 1998; 23(138): 2735.

7. Jane D. Siegel, MD; Emily Rhinehart, RN MPH CIC; Marguerite Jackson, PhD; Linda Chiarello, RN MS; the Healthcare Infection Control Practices Advisory Committee, Management of Multidrug-Resistant Organisms In Healthcare Settings, 2006. Disponível em: http://www.cdc.gov/ncidod/dhqp/pdf/ar/mdroGuideline2006.pdf

8. Santos SLV, Sousab TK, Costa DM, Lopes LKO, Pelejad EB, Sousa DM, Palos MAP, Pereira MS. Infecciones asociadas a la atención de salud en un Hospital de Oncología Brasileño: análisis de cinco años. Enferméria Global. 2012; (5): 8-17.

9.Sapolnik, R. Intensive care therapy for cancer patients. Jornal de Pediatria. 2003; 79(2): 231-42.

10. Agência Nacional de Vigilância Sanitária (Brasil). Medidas para identificação, prevenção e controle de infecções relacionadas à assistência à saúde por microrganismos multirresistentes. Brasília: Agência Nacional de Vigilância Sanitária, 2010.

11. Clinical and Laboratory Standards Institute. Methods for Dilution Antimicrobial Susceptibility Tests for Bacteria That Grow Aerobically; Approved Standard. Pennsylvania, 2009.

12. Prado-Palos MA, Gir E, Lima ABM, Leão LSNO, Pimenta FC. Prevalência de bastonetes Gram-negativos isolados da saliva de trabalhadores da saúde. Rev. Eletr. Enf. [Internet]. 2011 [acesso em: 31 de julho de 2012]; 13(4): 730-4. Disponível em: http://www.fen.ufg.br/revista/v13/n4/v13n4a18.htm

13. Coia JE, Duckworth GJ, Edwards DI, Farrington M, Fry C, Humphreys H, Mallaghan C, Tucker DR, et al. For the joint working party of the British Society of Antimicrobial chemotherapy, the Hospital Infection Society, and the Infection Control Nurses Association Guidelines for the control and prevention of meticilin-resistant Staphylococcus aureus (MRSA) in healthcare facilities. J Hosp Infect. 2006; 63:S144.

14. Silva ECBF, Antas MGC, Neto AMN, Rabelo MA, Melo FL, Maciel MAV. Prevalência e fatores de risco para Staphylococcus aureus em profissionais de saúde em um hospital universitário de Recife-PE. Braz J Infect Dis. 2008; 12(6): 504508. Disponível em: http://www.scielo.br/scielo.php?script=sci_arttext\&pid=S1413$86702008000600012 \& \operatorname{lng}=\mathrm{en}$

15. Cavalcanti SMM, França ER, Cabral C, Vilela MA, Montenegro F, Menezes D, Medeiros ACR. Prevalência de Staphylococcus aureus introduzido em unidades de 
terapia intensiva de um hospital universitário. Braz J Infect Dis. 2005; 9(1): 5663. Disponível em: http://www.scielo.br/scielo.php?script=sci_arttext\&pid=S141386702005000100010\&lng=en. http://dx.doi.org/10.1590/S1413-86702005000100010. 16. Rosa JO, Moura JPJ, Palos MAP, Gir E, Reis C, Kipnis A, Canini SR, BelissimoRodrigues F, Pimenta FC. Detecção do gene mecA em estafilococos coagulase negativa resistentes à oxacilina isolados da saliva de profissionais da enfermagem. Rev. Soc. Bras. Med. Trop. 2009; 42(4): 398-403. Disponível em: <http://www.scielo.br/scielo.php?script=sci_arttext\&pid=S0037-86822009000400008> 17.Huang SY, Tang RB, Chen SJ, Chung RL. Coagulase-negative staphylococcal bacteremia in critically ill children: risk factors and antimicrobial susceptibility. The Journal of Microbiology, Immunology and Infection. 2003; 36: 51-55,

18. Góngora-Rubio F, Pignatari ACC, Costa LMD, Bortolloto VI, Machado AM, Góngora DVN. Significância clínica, epidemiologia e microbiologia das bacteremias por estafilococos coagulase-negativos em Hospital de Ensino. Rev Ass Med Brasil. 1997; 43(1): 9-14.

19. Prado MA. Staphylococcus aureus e Staphylococcus aureus meticilina resistentes (MRSA) em profissionais de saúde e as interfaces com as infecções nosocomiais. Rev. Eletr. Enf. [Internet]. 2007; [acesso em 03 de agosto de 2012]; 9(3): 880-2. Disponível em: <http://www.fen.ufg.br/revista/v9/n3/v9n3a27.htm>

20. Moura JP, Pimenta FC, Hayashida M, Cruz EDA, Canini SRMS, Gir E. A colonização dos profissionais de enfermagem por Staphylococcus aureus. Rev. Latino-Am. Enfermagem [Internet]; 2011 [acesso em: 01 de agosto de 2012]; 19(2): [07 telas]. Disponível em: <http://www.scielo.br/pdf/rlae/v19n2/pt_14.pdf>

21. Ibarra M, Tristan F, Van Maele D, Aisha A, Fergie J, Purcell K. Prevalence of Methicillin-Resistant Staphylococcus Aureus Nasal Carriage in Healthcare Workers. Pediatric Infectious Disease Journal. 2008;27(2): 1109 -11.

22. Silva ECBF, Samico TM, Cardoso RR, Rabelo MA, Neto AMB, Melo FL, et all. Colonização pelo Staphylococcus aureus em profissionais de enfermagem de um hospital escola de Pernambuco. Rev Esc Enferm USP. 2012; 46(1):132-7

23. Oliveira $A C$, Silva RS. Desafios do cuidar em saúde frente à resistência bacteriana: uma revisão. Rev. Eletr. Enf. [Internet]. 2008;10(1):189-197. Disponível em: http://www.fen.ufg.br/revista/v10/n1/v10n1a17.htm

24. Agência Nacional de Vigilância Sanitária (Brasil). Boletim Informativo sobre segurança do paciente e qualidade assistencial em saúde. 2011; 1 (1)1: 12 p.

25. Barreto, R. A. S. S. et. al. Higienização das mãos: a adesão entre os profissionais de enfermagem da sala de recuperação pós-anestésica. Rev. Eletr. Enf. 2009; 11(2): 334-40, Disponível em: <http://www.fen.ufg.br/revista/v11/n2/v11n2a14.htm>

26. Mendonça AP, Fernandes MSC, Azevedo JMR, Silveira WCR, Souza ACS. Lavagem das mãos: adesão dos profissionais de saúde em uma unidade de terapia intensiva neonatal. Acta Scientiarum. 2003;25(2): 147-153.

27. Palos MAP, Silva DVB, Gir E, Canini SRMS, Anders PS, Leão LSNO, Pimenta FC. Microbiota das mãos de mães e de profissionais de saúde de uma maternidade de Goiânia. Rev. Eletr. Enf. [Internet]. 2009;11(3):573-8. Disponível em: <http://www.fen.ufg.br/revista/v11/n3/v11n3a14.htm>

28. Martinez MR, Campos, LAAF, Nogueira PCK. Adesão à técnica de lavagem de mãos em Unidade de Terapia Intensiva Neonatal. Rev Paul Pediatr. 2009; 27(2):17985.

29. Oliveira DGM, Souza PR, Watanabe E, Andrade D. Avaliação da higiene das mãos na perspectiva microbiológica. Rev Panama Infectol. 2010; 12(3): 28-32.

30. Altoparlak U, Kadanali A, Celebi S. Slime factor positivity in coagulase-negative staphylococci isolated from nasal samples of haemodialysis patients. Int J Clin Pract. 2004; 58:1112-4 
31. ANVISA. Segurança do paciente em serviços de saúde. Brasília, DF, 2007. Acesso em 01 de agosto de 2012. Disponível em: http://www.anvisa.gov.br/servicosaude/controle/higienizacao_oms.htm 32. Palos MAP, Costa DM, Gir E, Pimenta FC. Atuação de enfermagem em Unidades de Terapia Intensiva: implicações para disseminação de micro-organismo multirresistente. Rev Panam Infectol. 2010;12(1): 37-42.

33. OMS - Organização Mundial da Saúde. Diretrizes da OMS sobre higienização das mãos na assistência à saúde: Resumo. Genebra: OMS; 2005. 